\title{
FACIAL SENSORY SYMPTOMS IN MEDULLARY INFARCTS
}

\author{
Adriana Bastos Conforto', Fábio luji Yamamoto', Cláudia da Costa Leite², \\ Milberto Scaff', Suely Kazue Nagahashi Marie ${ }^{1}$
}

\begin{abstract}
Objective: To investigate the correlation between facial sensory abnormalities and lesional topography in eight patients with lateral medullary infarcts (LMIs). Method: We reviewed eight sequential cases of LMls admitted to the Neurology Division of Hospital das Clínicas/ São Paulo University between July, 2001 and August, 2002 except for one patient who had admitted in 1996 and was still followed in 2002. All patients were submitted to conventional brain MRI including axial T1-, T2-weighted and Fluid attenuated inversion-recovery (FLAIR) sequences. MRIs were evaluated blindly to clinical features to determine extension of the infarct to presumed topographies of the ventral trigeminothalamic (VTT), lateral spinothalamic, spinal trigeminal tracts and spinal trigeminal nucleus. Results: Sensory symptoms or signs we re ipsilateral to the bulbar infarct in 3 patients, contralateral in 4 and bilateral in 1 . In all of our cases with exclusive contralateral facial sensory symptoms, infarcts had medial extensions that included the VTT topography. In cases with exclusive ipsilateral facial sensory abnormalities, infarcts affected lateral and posterior bulbar portions, with slight or no medial extension. The only patient who presented bilateral facial symptoms had an infarct that covered both medial and lateral, in addition to the posterior region of the medulla. Conclusion: Our results show a correlation between medial extension of LMIs and presence of contralateral facial sensory symptoms.
\end{abstract}

KEY WORDS: ventral trigeminothalamic tract, spinal trigeminal nucleus, ischemic stroke, Wallenberg syndrome.

\section{Sintomas sensitivos na face em infartos medulares}

RESUMO - Objetivo: Investigar a correlação entre alterações de sensibilidade na face e topografia lesional em oito pacientes com infartos bulbares laterais (IBLs). Método: Revisamos oito casos seqüenciais de IBLs admitidos na Divisão de Clínica Neurológica do Hospital das Clínicas da Universidade de São Paulo entre julho de 2001 e agosto de 2002, exceto por um caso que havia sido admitido em 1996 e estava sendo seguido em 2002. Todos os pacientes foram submetidos a ressonância magnética de encéfalo, incluindo seqüências pesadas em T1, T2 e FLAIR. As ressonâncias foram avaliadas por investigadores que não tiveram acesso às características clínicas. Avaliaram-se as extensões dos infartos em relação às topografias presumidas dos tratos trigeminotalâmico ventral (TTV), espinotalâmico lateral, trigeminal espinhal e do núcleo trigeminal espinhal. Resultados: Sintomas ou sinais sensitivos foram ipsilaterais ao infarto bulbar em 3 pacientes, contralaterais em 4 e bilaterais em 1. Em todos os casos de comprometimento exclusivo da sensibilidade da hemiface contralateral, os infartos tiveram extensões mediais que incluíram a topografia do TTV. Em casos de anormalidades sensitivas faciais exclusivamente ipsilaterais, os infartos afetaram as porções lateral e posterior do bulbo, com pouca ou nenhuma extensão medial. $O$ único paciente que apresentou sintomas faciais bilaterais tinha um infarto comprometendo as porções medial e lateral, além da região posterior do bulbo. Conclusão: Nossos resultados mostram uma correlação entre extensão medial de IBLs e presença de sintomas sensitivos faciais contralaterais.

PALAVRAS-CHAVE: trato trigeminotalâmico ventral, núcleo trigeminal espinhal, síndrome de Wallenberg.

Wallenberg's syndrome (WS) is usually caused by infarction of the lateral portion of the medulla, more often caused by vertebral artery (VA) disease $^{1-3}$. In classical WS, pain and temperature sensation loss on the face is ipsilateral to the lesion in the medulla. However, contralateral and bilateral sensory abnormalities may also occur ${ }^{4-7}$.

In neuroanatomical descriptions of the brain stem, the descending spinal nucleus/tract (DSN/T) and the ventral ascending tract of the trigeminal

\footnotetext{
${ }^{1}$ Ne u rology Division, Hospital das Clínicas, São Paulo University, São Paulo SP, Brazil (HC/FMUSP); ${ }^{2}$ Radiology Department, HC/FMUSP Received 9 March 2005, received in final form 24 August 2005. Accepted 5 September 2005. 
ne ve or ventral trigeminothalamic tract (VTT) are located in the posterolateral medulla ${ }^{1,4}$. The VTT is positioned adjacent to the medial lemniscus or medial to the lateral spinothalamic tract (LST) in the dorsomedial corner of the inferior olive (Fig $1)^{4}$. DSN/T lesions are associated with decrease in pain and temperature sensation on the ipsilateral face, while injuries to the VTT crossing fibers $p$ roduce diminished sensation on the contralateral face ${ }^{4,8}$. Thus, it would be expected that infarcts extending medially and anteriorly in the dorsolateral medulla would cause pain and temperature sensoryloss on the contralateral face, opposite to the side of the lesion.

Some studies reported lateral medullary infarcts (LMIs) to be more medially located in patients with contralateral facial pain/temperature sensory loss than in those with ipsilateral facial sensory abnormalities ${ }^{4,9}$ but others did not confirm these findings $^{8}$. We have investigated the correlation between facial sensory abnormalities and involvement of the VTT topography in eight patients with medullary infarcts (Mls).

\section{METHOD}

There were 5 men and 3 women ranging in age from 40 to 64 years (one less than 45 years), admitted to the Neurology Division of Hospital das Clínicas/ São Paulo University between July, 2001 and August, 2002 except for one patient who had been admitted in 1996 and was still been followed in 2002. Vascular risk factors we re arterial hypertension $(n=4)$, diabetes mellitus $(n=2)$, smoking $(n=6)$ and Chagas' disease $(n=1)^{10}$. All of the patients were evaluated by the Neurology Division staff. Side and type of sensory findings on the face, arm and/or leg, as well as other neurological symptoms and signs we re reviewed. Investigation included biochemical and serological testing, electrocardiogram, chest radiography, echocardiogram, cervical Doppler ultrasound, cranial computed tomography (CT), magnetic resonance imaging (MRI) and magnetic resonance angiography (MRA). Digital subtraction angiography (DSA) and transcranial Doppler were performed in 4 and 2 patients, respectively. Patients less than 45 years were submitted to exhaustive haematologic, immunologic and cere b rospinal fluid analysis. Criteria of the Lausanne Stroke Registry were used to define presumed causes of infarction ${ }^{11}$.

All patients were submitted to conventional brain MRI including axial T1-, T2-weighted and Fluid attenuated inversion-re c o v e ry (FLAIR) sequences from a 1.5-T MR unit (GE Signa System, General Electric). Diffusionweighted images (DWI) were performed in 3 patients.

The investigator evaluated MRI lesional topography based on transverse anatomical templates of the medulla oblongata ${ }^{4}$ (Fig 1, left) was blind to patient history and neurological examination. Two lines were drawn on the transverse MRI section demonstrating the MI. Line 1 divided each hemi-medulla in anterior and posterior regions. Line 2 bisected Line 1, dividing the hemimedulla in medial and lateral regions. Medullary sections were also classified as rostral (massive bulging of the restiform body), middle (bulging of the inferior olive) and caudal (relatively round shape without bulging of the lateral surface) ${ }^{3}$.

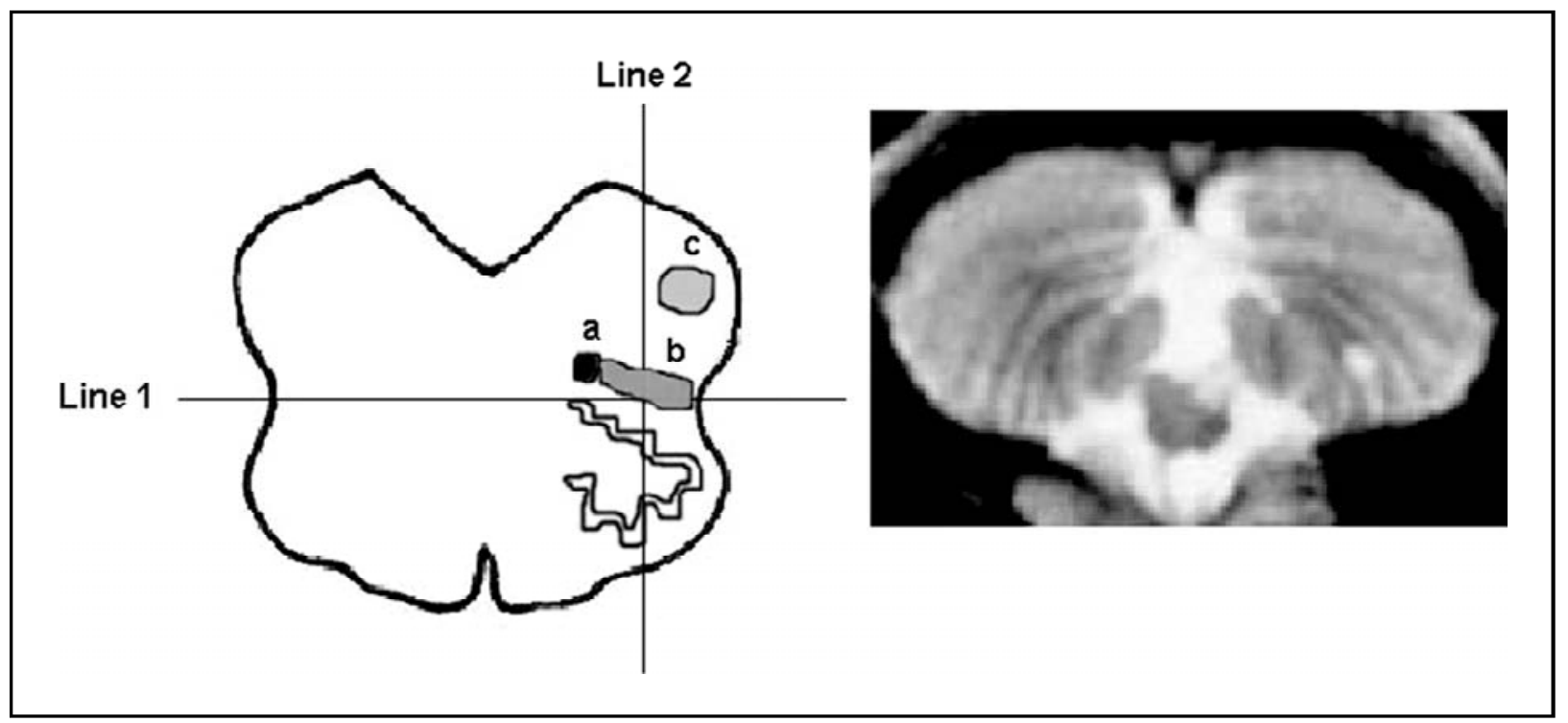

Fig 1. Left. Schematic re p resentation of the middle portion of the medulla. Line 1 divides the hemi-medulla in anterior and posterior regions and line 2, in medial and lateral regions. Topographies of yhe ventral trigeminothalamic tract; (a), lateral spinothalamic tract (b) and spinal trigeminal tract and nucleus (c) are indicated. Right. T2-weighted MRI showing infarct in Case 8, extending medially and laterally. 


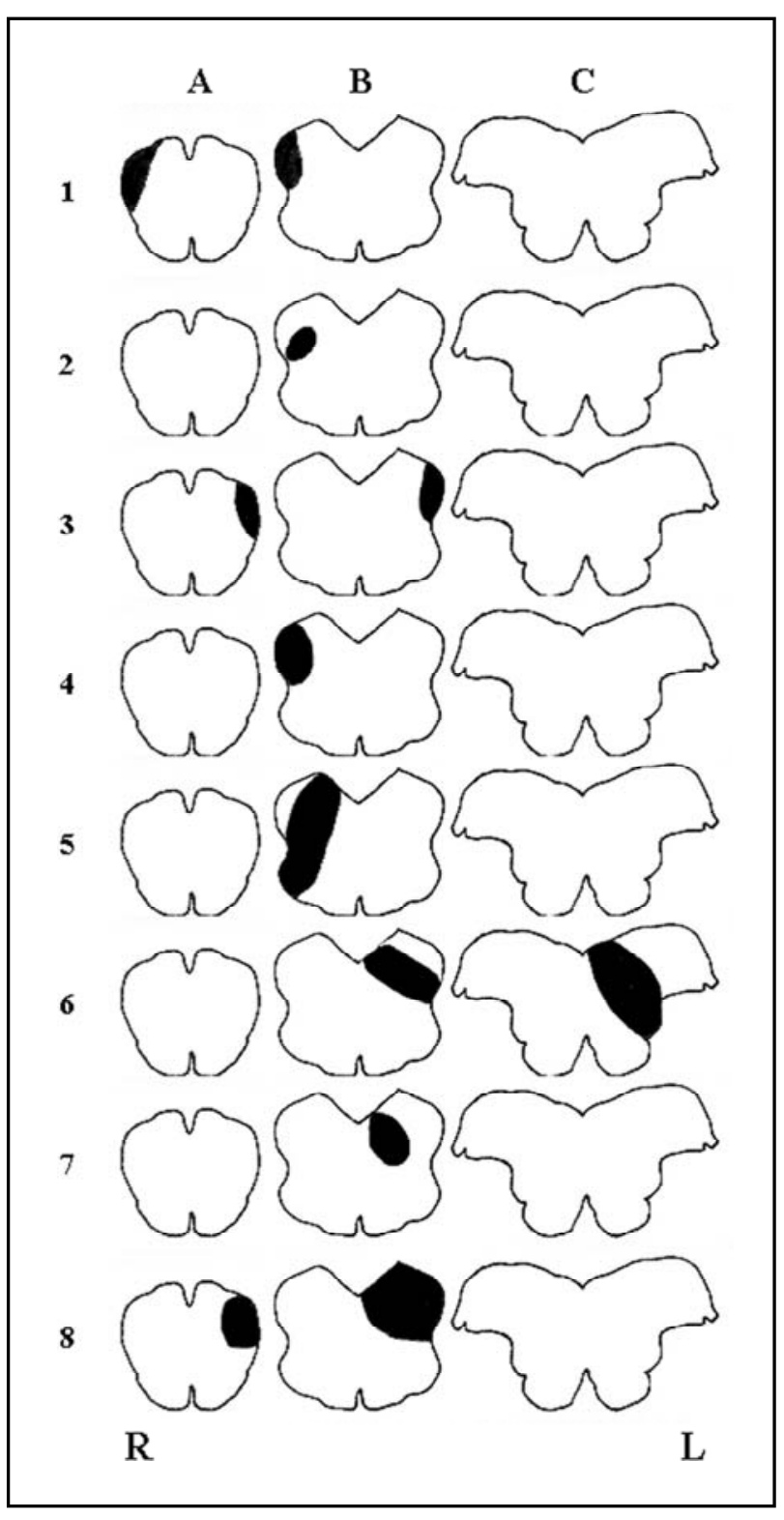

Fig 2. Schematic representations of infarcts in Cases 1-8 in me dullary levels: A (caudal), B (middle) and C (rostral.)

\section{RESULTS}

There were 4 right and 4 left Mls. Characteristics of the 8 cases are shown in the Table. All of the patients had sensory abnormalities: 7 patients had pain and/ or temperature hypesthesia and 4 patients had facial paresthesias. Deep sensation was normal in all of them. Sensory symptoms or signs were ipsilateral to the bulbar infarct in 3 patients $(37.5 \%)$, contralateral in $4(50 \%)$ and bilateral in $1(12.5 \%)$.

In all of the patients with facial sensory abnormalities ipsilateral to the lesion (Cases 1-3), Mls included lateral and posterior medullary regions.
In Cases 1 and 2, infarcts had also slight medial extensions. In all of the patients with contralateral facial symptoms or signs (Cases 4-7), infarcts had g reater medial extension than in Cases 1-3 (Fig 2, Table). In Case 8, the patient had bilateral facial symptoms and the lesion also extended medially in the medulla (Fig 1, right).

The middle portion of the medulla was affected in all infarcts. In cases 1, 3 and 8, there was also involvement of the caudal medulla (Fig 2). Two of these patients had exclusive ipsilateral facial symptoms and the other patient, bilateral symptoms. Unilateral cerebellar infarcts, ipsilateral to the bulbar lesion, were present in Cases 2-5 and bilateral infarcts, in Case 8. Glossopharyngeal and vagus ne ne involvement was present in 6 of these cases $(85.7 \%)$; miosis and ptosis occurred in $5(71.4 \%)$; limb and/or gait ataxia were found in $3(42.8 \%)$.

VA atherosclerosis was the presumed mechanism of infarction in all of the 3 patients with ipsilateral facial sensory symptoms. Atherosclerosis was the presumed mechanism in 1 of the patients with contralateral symptoms (Case 4). In the other 4 patients, mechanisms were undetermined but VA or posterior inferior cerebellar artery (PICA) dissections were considered probable candidate stroke mechanisms in 3 patients (Cases 5, 7 and 8).

\section{DISCUSSION}

Our findings suggest that contralateral facial sensory abnormalities are related to medial extension of the infarct and lack of contralateral symptoms, to absence of medial involvement in agre ement with other reports ${ }^{4,9}$. Case 8 presented a truncal sensory level. Such a finding has been previously re ported in LMIs ${ }^{4}$. Case 3 had arm pare sthesias ipsilaterally to the LMI. This pattern of sensory abnormality has also been described ${ }^{9}$.

Based on current neuroanatomical information and meticulous neurological evaluation, Currier and colleagues ${ }^{12}$ associated sensory symptoms contralateral to the LMI to ventral and dorsoventral syndromes. More than twenty years later, Matsumoto and colleagues ${ }^{4}$ co rrelated imaging findings and neurological symptoms, concluding that patients with LMls and contralateral facial symptoms had lesions more medially located than those with ipsilateral sensory defects. In a patient with bilateral facial symptoms, lesions encopassed both DSN/T and VTT projections. In four patients with medullary infarcts confirmed by MRI, two had ipsi- 
Table. Neurological symptoms/signs and side of medullary infarctions and location of lesions rostrocaudally/medial-laterally $(n=8)$.

\begin{tabular}{|c|c|c|c|c|c|c|c|c|c|c|c|}
\hline Case & $\begin{array}{c}\text { Side of } \\
\text { sensory } \\
\text { symptom/ } \\
\text { sign (face) }\end{array}$ & $\begin{array}{l}\text { Side of } \\
\text { bulbar } \\
\text { infarction }\end{array}$ & $\begin{array}{c}\text { Sensory } \\
\text { symptom/ } \\
\text { sign } \\
\text { (face) }\end{array}$ & $\begin{array}{c}\text { Sensory } \\
\text { symptom/ } \\
\text { sign (limbs) }\end{array}$ & Lateral & Medial & Anterior & Posterior & Caudal & Middle & Rostral \\
\hline 1 & $R$ & $\mathrm{R}$ & $P$ & Absent & + & \pm & - & + & + & + & - \\
\hline 2 & $R$ & $\mathrm{R}$ & HP & $\begin{array}{l}\mathrm{L} \text { arm and } \\
\text { leg } \mathrm{P} \text { and } \mathrm{HP}\end{array}$ & + & \pm & - & + & - & + & - \\
\hline 3 & L & L & $\mathrm{P} / \mathrm{HP}$ & $\mathrm{L}$ arm $\mathrm{P}$ & + & - & - & + & + & + & - \\
\hline 4 & L & $\mathrm{R}$ & HP & $\begin{array}{l}\mathrm{L} \text { arm and } \\
\text { leg } \mathrm{P} \text { and } \mathrm{HP}\end{array}$ & + & + & - & + & - & + & - \\
\hline 5 & L & $\mathrm{R}$ & $\mathrm{P} / \mathrm{HP}$ & R arm HP & + & + & \pm & + & - & + & - \\
\hline 6 & $R$ & L & HP & $\begin{array}{l}\mathrm{R} \text { arm and } \\
\text { leg HP }\end{array}$ & + & + & - & + & - & + & + \\
\hline 7 & $\mathrm{R}$ & L & HP & R arm HP; & - & + & - & + & - & + & - \\
\hline 8 & $R / L$ & L & $\mathrm{P} / \mathrm{HP}$ & $\begin{array}{l}\text { left arm and } \\
\text { leg } \mathrm{P}+\mathrm{HP} ; \\
\text { right leg } \mathrm{P} \\
\text { right trunk } \\
\text { and leg HP } \\
\text { with T8 } \\
\text { sensory level }\end{array}$ & + & + & - & + & + & + & - \\
\hline
\end{tabular}

$P$, paresthesias; $H P$, pain/temperature hypesthesia; $R$, right; $L$, left.

lateral, one contralateral and one, bilateral sensory abnormalities. On the other hand, Chia and colleagues did not find an association between LMI location and side of facial sensory abnormalities ${ }^{4,8}$. They reported $53.8 \%$ of ipsilateral and $46,2 \%$ of contralateral facial sensory loss in 13 patients. Likewise, in a series of 130 patients with pu re LMIs, no significant correlations were found between horizontal patterns of infarction and ipsilateral or contralateral sensory symptoms6. Ipsilateral, contralateral and bilateral facial symptoms or signs were described respectively in $26 \%, 25 \%$ and $8 \%$ of the patients. Comparisons were made between 5 groups of lesions. In 3 of these groups ("typical", "large" and "ventral"; n=59) lesions extended medially and therefore, potentially involved the VTT while in the other 2 groups ("lateral" and "dorsal", n=9), VTT topography was spared. Specific comparisons between facial sensory symptoms and infarcts involving or not the VTT topography were not performed. However, if the data from the first 3 groups had been pooled and compared with combined results from the last 2 groups, facial symptoms in lesions potentially enco- passing VTT topography would be contralateral or bilateral in 42/59 (71.2\%) patients and ipsilateral in $17 / 59(28.8 \%)$, while in lesions sparing the VTT, contralateral or bilateral symptoms would occur in $1 / 9(11.1 \%)$ and ipsilateral symptoms, in $8 / 9$ patients $(88.9 \%)$.

Diffe rent criteria for classification of lesional topography may partially explain discrepancies in the literature. However, differences in mechanisms of stroke and anatomical PICA and VA variations may also contribute to conflicting results in different series of patients. The lateral medulla is more often supplied by perforating branches from the VA, and less frequently through the medial PICA branch or the proximal basilar artery ${ }^{3,9,13}$. It has been suggested that the speed of vascular lesion development as well as collateral blood flow have a major role in defining imaging and clinical characteristics in $\mathrm{Mls}^{3}$. In the present series, VA atherosclerosis was the probable cause in 2 patients with ipsilateral facial involvement and the possible mechanism in the third case. Among 5 cases with contralateral or bilateral sensory loss, VA or PICA 
dissections were considered likely stroke mechanisms in 3 patients.

Sensory symptoms and signs have been found to be the most common neurological manifestation in LMls ${ }^{6,14}$. Our results confirm the correlation between medial extension of the infarct involving VTT topography, and side of facial sensory symptoms, as previously described ${ }^{4}$. Simultaneous comparisons between side of sensory facial symptoms, topography of medullary lesions and presumed causes of stroke according to complete neurovascular investigation should be performed in a larger series of patients in order to determine whether characteristics of facial sensory symptoms and signs can also be related to LMI mechanisms.

\section{REFERENCES}

1. Roig C, Barraquer-Bordas L. History of Wallenberg's syndrome. Rev Neurol 1996;24:96-100.

2. Sacco RL, Freddo L, Bello JA, Odel JG, Onesti ST, Mohr JP. Wallenberg's lateral medullary syndrome: clinical-magnetic resonance imaging correlations. Arch Neurol 1993;50:609-614.

3. Kim JS, Lee JH, Suh DC, Lee MC. Spectrum of lateral medullary syn$\mathrm{d}$ rome: correlation between clinical findings and magnetic resonance imaging in 33 subjects. Stroke 1994;25:1405-1410.
4. Matsumoto S, Okuda B, Imai T, Kameyama M. A sensory level on the t runk in lower lateral brainstem lesions. Neurology 1988;38:1515-1519.

5. Bogousslavsky J, Regli F, Maeder P, Meuli R, Nader J. The etiology of posterior circulation infarcts: a prospective study using magnetic resonance imaging and magnetic resonance angiography. Neurology 1993;43:1528-1533.

6. Kim JS. Pure lateral medullary infarction: clinical-radiological correlation of 130 acute, consecutive patients. Brain 2003;126:1864-1872.

7. Kim JS, Lee JH, Choong CG. Patterns of lateral medullary infarction: vascular lesion-magnetic resonance imaging correlation of 34 cases. Stroke 1998;29:645-652.

8. Chia LG, Shen WC. Wallenberg's lateral medullary syndrome with loss of pain and temperature sensation on the contralateral face: clinical, MRI and electrophysiological studies. J Neurol 1993;240:462-467 .

9. Vuilleumier P, Bogousslavsky J, Regli F. Infarction of the lower brainstem: clinical, aetiological and MRI- topographical correlations. Brain 1995;118:1013-1025.

10. C a rod-Artal FJ, Va rgas AP, Melo M, Horan TA. American trypanosomiasis (Chagas' disease): an unrecognised cause of stroke. J Neurol Neurosurg Psychiatry 2003;74:516-518.

11. Bogousslavsky J, Van Melle G, Regli F. The Lausanne Stroke Registry: analysis of 1,000 consecutive patients with first stroke. Stroke 1988;19:1083-1092.

12. Currier RD, Giles CL, De Jong RN. Some comments on Wallenberg's lateral medullary syndrome. Neurology 1961;11:778-791.

13. Ama renco $P$, Roullet $E$, Hommel M, Chaine P, Marteau R. Infarction in the territory of the medial branch of the posterior inferior cerebellar artery. J Neurol Neurosurg Psychiatry 1990;53:731-735.

14. Kameda W, Kawanami T, Kurita K, et al. Lateral and medial medullary infarction. Stroke 2004;35:694-703. 